\title{
Propofol protects against endotoxin-induced myocardial injury by inhibiting NF-kB-mediated inflammation
}

\author{
ZHIJUN YANG ${ }^{1 *}$, FENG CHENG ${ }^{2 *}$, GUOSHENG YAN $^{1}$, LANG XIONG $^{1}$ and HUIZHANG LIU ${ }^{1}$ \\ Departments of ${ }^{1}$ Anesthesiology and ${ }^{2}$ Clinical Laboratory, Ezhou Central Hospital, Ezhou, Hubei 436000, P.R. China
}

Received July 7, 2017; Accepted November 22, 2017

DOI: $10.3892 /$ etm.2017.5605

\begin{abstract}
This study investigated whether propofol protects against endotoxin-induced myocardial injury by inhibiting $\mathrm{NF}-\kappa \mathrm{B}-$ mediated inflammation. Thirty clean male SD rats were randomly divided into a control $(n=10)$, a model $(n=10)$ and a propofol group $(n=10)$. The model and propofol groups were injected with lipopolysaccharide (LPS) via the caudal vein to establish animal models of myocardial injury. At the same time, the control group was injected with normal saline via the caudal vein. At $30 \mathrm{~min}$ after the injections, the propofol group was treated with a continuous intravenous infusion of propofol, the control and model groups were injected with normal saline, and the three groups were treated continuously for $4 \mathrm{~h}$. The changes in levels of interleukin-1 (IL-1), interleukin-6 (IL-6) and tumor necrosis factor- $\alpha$ (TNF- $\alpha$ ) in serum were detected via enzyme-linked immunosorbent assay (ELISA). The mRNA expression level of nuclear factor- $\kappa \mathrm{B}$ $(\mathrm{NF}-\kappa \mathrm{B})$ in myocardial tissues was detected via quantitative real-time polymerase chain reaction (qRT-PCR). The protein expression levels of $\mathrm{NF}-\kappa \mathrm{B}, \mathrm{Bax}$ and $\mathrm{Bcl}-2$ in atrial muscles in each group were measured via Western blotting. The damage of myocardial tissues was detected via hematoxylin eosin (H\&E) staining of tissues. Our results showed that compared with those in control group, the levels of IL-1, IL- 6 and TNF- $\alpha$ in serum in the model and propofol groups were significantly higher; however, the levels in the model group, were significantly higher than those in the propofol group $(\mathrm{P}<0.01)$. The mRNA and protein expression levels of $N F-\kappa B$ in the propofol group were significantly lower than those in the model group $(\mathrm{P}<0.01)$. Likewise, the protein expression levels of Bax were significantly lower, while those of Bcl-2 were significantly increased. H\&E staining showed that the myocardial tissues in
\end{abstract}

Correspondence to: Dr Huizhang Liu, Department of Anesthesiology, Ezhou Central Hospital, 9 Wenxing Avenue, Ezhou, Hubei 436000, P.R. China

E-mail: drhuichangliu@163.com

${ }^{*}$ Contributed equally

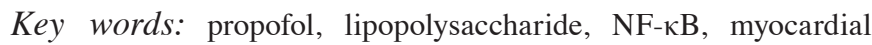
injury, IL-1, IL-6, TNF- $\alpha$ the model group were damaged significantly, but the damage in the propofol group was significantly less severe. Based on our findings, it seems propofol can indeed protect against endotoxin-induced myocardial injury through its inhibition of

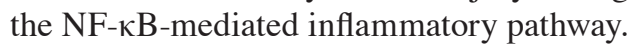

\section{Introduction}

Endotoxemia is a common systemic inflammatory response caused by the release of large amounts of endotoxin produced by Gram-negative bacteria into the bloodstream (1-3). Lipopolysaccharide (LPS) is the main component of endotoxin. When the ligand LPS binds to its signal receptor on the cell membranes, it can activate signal pathways to initiate the natural immune defense response of the body (4,5). A systemic inflammatory response syndrome (SIRS) is the main symptom of endotoxemia, which progresses to involve multiple organ without timely and effective treatment; the heart is one of the most severly affected organs. If the cardiac complication occurs and the disease cannot be effectively controlled, the mortality rate reaches $50-60 \%$ (6,7). Myocardial injury caused by endotoxemia is an important cause of death, but its pathogenic mechanism has not been entirely elucidated (8).

Propofol, which is widely used in clinical anesthesia, can induce coronary dilatation. A large number of clinical tests have made a comprehensive evaluation of propofol, suggesting that it can effectively protect myocardial cells from ischemiareperfusion injury, and that it has significant anti-inflammatory effects $(9,10)$. However, reports on the anti-inflammatory effect of propofol in the context of endotoxin-induced myocardial injury are lacking. Nuclear factor- $\kappa \mathrm{B}(\mathrm{NF}-\kappa \mathrm{B})$, as a marker of the inflammatory response, not only regulates the transcriptional expression levels of various inflammatory factors, but also plays a certain role in apoptosis (11).

In this study, we hypothesized propofol can be used in the clinical treatment of endotoxemia and septic shock. Rats with endotoxin-induced myocardial injury were treated with propofol, and the effect of the treatment on myocardial injury and its possible mechanism were studied via in vivo experiments.

\section{Materials and methods}

Experimental animals and grouping. Thirty clean and healthy male SD rats weighing 180-220 g were randomly divided into 
A

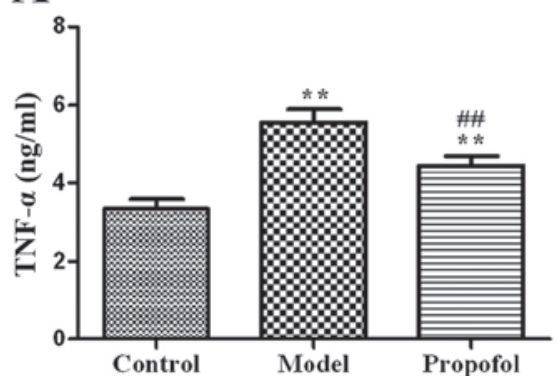

B

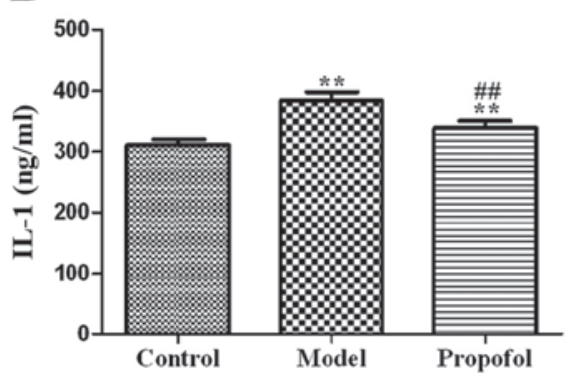

C

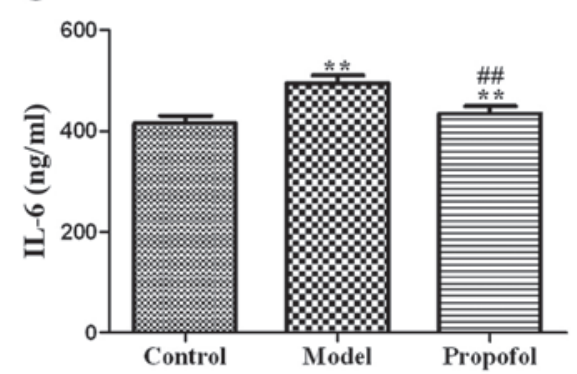

Figure 1. Graphic representation of the ELISA results for the effects of propofol on TNF- $\alpha$ (A), IL-1 (B), and IL-6 (C) levels in serum. Levels of IL-1, IL-6 and TNF- $\alpha$ in the model and propofol groups are significantly higher than those in the control group ( $\left.{ }^{* *} \mathrm{P}<0.01\right)$. Levels of IL-1, IL- 6 and TNF- $\alpha$ in the propofol group are significantly lower than those in the control group $\left({ }^{\# \#} \mathrm{P}<0.01\right)$.

3 groups (10 rats in each group). LPS ( $5 \mathrm{mg} / \mathrm{kg}$ ) (Sigma, New York, NY, USA) were injected via the caudal vein to establish the rat models of myocardial injury, and the control group rats received an intravenous injection of $0.5 \mathrm{ml}$ normal saline via the caudal vein. After $30 \mathrm{~min}$, the rats in the control and model groups were injected with $1 \mathrm{ml} / \mathrm{kg} / \mathrm{h}$ normal saline, and the rats in the propofol group were injected with $4 \mathrm{mg} / \mathrm{kg}$ propofol (AstraZeneca, Cambridge, UK; batch number: 0802193) via the caudal vein. An infusion with $8 \mathrm{mg} / \mathrm{kg} / \mathrm{h}$ propofol and another one with normal saline were initiated for the rats in the propofol group and those in the model and control groups, respectively. The total infusions lasted $4 \mathrm{~h}$ in all the rats. While still under anesthesia, blood was collected from the abdominal aorta and then rats were sacrificed. The chest was opened to take out the heart. A portion of myocardium was stored at $-80^{\circ} \mathrm{C}$, and a portion was fixed with $10 \%$ neutral formaldehyde solution. The study was approved by the Ethics Committee of Ezhou Central Hospital.

Detection of IL-1, IL-6 and TNF- $\alpha$ levels via ELISA. Arterial blood was collected from the rats and then centrifuged at $2,010 \mathrm{x} \mathrm{g}$ for $10 \mathrm{~min}$ at $4^{\circ} \mathrm{C}$, and the separated serum was saved for detection. The levels of IL-1, IL- 6 and TNF- $\alpha$ in serum from each rat were measured via ELISA strictly according to the manufacturer's instructions (Nanjin Jiancheng Biotechnology, Nanjin, China). In the experiment, each sample was detected 3 times, and each average value was recorded.

Detection of $m R N A$ expression of $N F-\kappa B$ in myocardial tissues of rats via qRT-PCR. Total RNA was extracted from the myocardial tissues of each rat according to the method provided in the TRIzol kit (Beyotime Biotechnology Institute, Nantong, China), and the concentration and purity of RNA were measured. When the A260/A280 ratio was between 1.8 and 2.0, it was deemed of good quality. Next, reverse transcription and qPCR were performed following the instructions in the reverse transcription, and quantitative real-time polymerase chain reaction (qRT-PCR) kits (Takara, Dalian, China). The mRNA expression was detected using the cDNA obtained after reverse transcription as the template according to the instructions of qRT-PCR kit. The primer sequences (Takara) are shown in Table I. The qPCR reaction conditions included $94^{\circ} \mathrm{C}$ for $5 \mathrm{~min}$, and then 35 cycles of $94^{\circ} \mathrm{C}$ for $30 \mathrm{sec}, 57^{\circ} \mathrm{C}$ for $30 \mathrm{sec}$, and $72^{\circ} \mathrm{C}$ for
$30 \mathrm{sec}$, followed by a final extension at $72^{\circ} \mathrm{C}$ for $5 \mathrm{~min} . \mathrm{Ct}$ values were obtained from the instrument, and the relative expression levels were calculated according to the following formula with GAPDH gene as the control gene: $\Delta \mathrm{Ct}$ (target gene $)=\mathrm{Ct}$ (target gene) $-\mathrm{Ct}$ (control gene) .

Detection of protein expression levels of $N F-\kappa B, B a x$ and Bcl-2 in myocardial tissues via western blotting. Atrial tissue samples from each rat were lysed with RIPA lysate buffer (Beyotime Biotechnology Institute) and centrifuged using a high-speed centrifuge for $5 \mathrm{~min}$. The supernatant was collected and the protein concentration was measured using the BCA protein concentration detection kit (Beyotime Biotechnology Institute). After ensuring the quality of the samples, $50 \mu \mathrm{g}$ protein were taken for $12 \%$ SDS-PAGE and membrane transfer. The separated proteins were transferred onto PVDF membranes. The membranes were sealed using sealing fluid at room temperature for $1 \mathrm{~h}$, and incubated with $\mathrm{NF}-\kappa \mathrm{B}, \mathrm{Bax}, \mathrm{Bcl}-2$ and GADPH antibodies (diluted at 1:500) overnight at $4^{\circ} \mathrm{C}$. Next, the membranes were washed fully with TTBS, and HRP-labeled secondary antibody (1:500) was used for incubation overnight at room temperature, followed by color development in the ECL darkroom, scanning and recording results. A grayscale analysis was performed with GADPH as the internal control protein. NF- $\kappa \mathrm{B}, \mathrm{Bax}, \mathrm{Bcl}-2$ and GADPH antibodies and HRP-labeled secondary antibody were purchased from Wuhan Proteintech Biotechnology (Wuhan, China).

Detection of myocardial injury via hematoxylin eosin $(H \& E)$ staining of tissues. Myocardial tissues were fixed and embedded into a paraffin block. Then, $5 \mu \mathrm{m}$-thick slices were cut into sections. The sections were stained with H\&E according to the conventional histopathological method. The stained sections were observed under a light microscope and photographed, before analyzing them using histopathological standards.

Statistical analysis. Data are presented as mean \pm standard deviation. SPSS 17.0 (IBM Corp., Armonk, NY, USA) software was used for data processing. One-way analysis of variance (ANOVA) was used to analyze the data and t-test was used for pairwise comparisons. A P-value of $<0.05$ was considered to indicate a statistically significant difference. 
Table I. qRT-PCR primer sequences.

\begin{tabular}{lc}
\hline Gene name & \multicolumn{1}{c}{ Primer sequence } \\
\hline NF-кB & F: 5'-GAAGAAGCGAGACCTGGAG-3' \\
& R: 5'-TCCGGAACACAATGGCCAC-3' \\
GAPDH & F: 5'-GGAAAGCTGTGGCGTGAT-3' \\
& R: 5'-AAGGTGGAAGAATGGGAGTT-3'
\end{tabular}

F, forward; R, reverse.

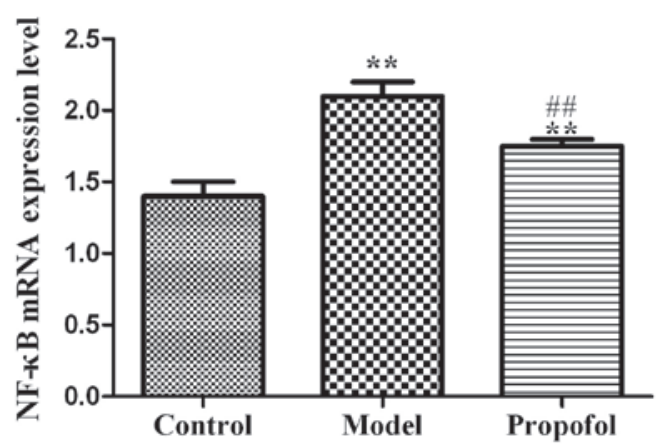

Figure 2. Graphic representation of NF- $\mathrm{BB}$ mRNA expression levels via qRT-PCR in the three groups. NF- $\mathrm{kB}$ mRNA expression levels in the model and propofol groups are significantly increased compared with those in the control group $\left.{ }^{(* *} \mathrm{P}<0.01\right)$. The expression levels in the propofol group were significantly lower than those in the model group $\left({ }^{(\#)} \mathrm{P}<0.01\right)$.

\section{Results}

Effects of propofol on IL-1,IL-6 and TNF- $\alpha$ levels in serum. The average levels of IL-1, IL- 6 and TNF- $\alpha$ in serum in the model and propofol groups were significantly higher than those in the control group $(\mathrm{P}<0.01)$. However, the average levels of IL-1, IL-6 and TNF- $\alpha$ in serum in the propofol group were significantly lower than those in the model group $(\mathrm{P}<0.01)$ (Fig. 1).

Effect of propofol on the mRNA expression of $N F-\kappa B$ in serum. The mRNA expression levels of NF- $\kappa \mathrm{B}$ in the control group were significantly lower than those in the model and propofol groups $(\mathrm{P}<0.01)$. Still, the $\mathrm{NF}-\kappa \mathrm{B}$ levels in the propofol group were significantly lower than those in the model group, $(\mathrm{P}<0.01)$ (Fig. 2).

Effects of propofol on the protein expression levels of $N F-\kappa B$, $\mathrm{Bax}$ and $\mathrm{Bcl}-2$. Compared to those in the normal control group, the $\mathrm{B}$ cell lymphoma-2 (Bcl-2) protein expression levels in the model and propofol groups were downregulated $(\mathrm{P}<0.01)$, but the expression levels of $\mathrm{Bax}$ and $\mathrm{NF}-\kappa \mathrm{B}$ were significantly upregulated $(\mathrm{P}<0.01)$. Moreover, the protein expression levels of Bcl-2 in the propofol group were upregulated compared with those in the model group $(\mathrm{P}<0.01)$, but the expression levels of Bax and $\mathrm{NF}-\kappa \mathrm{B}$ were significantly downregulated $(\mathrm{P}<0.01)$ (Fig. 3).

Detection of differences on myocardial injury in the three experimental groups via $H \& E$ staining. Myocardial tissues in the rats of the control group suffered no apparent injury. The myocardial tissues of rats in the model group were severely injured, coagulative necrotic lesions, lamellar necrosis, myocardial fiber breakage and partial dissolution were apparent. The myocardial injury of rats in the propofol group was significantly less severe than that of rats in the model group (Fig. 4).

\section{Discussion}

Gram-negative bacteria produce a large amount of endotoxin, and when it is released into the blood, it can cause a systemic inflammatory response (12). Once a systemic inflammatory response occurs, the death rate of patients is increased due to organ dysfunction, such as heart failure caused by myocardial injury (13). Propofol is a common anesthetic agent shown to possess anti-inflammatory effects (14). However, there is scarce research on whether propofol has a protective effect on endotoxin-induced myocardial injury.

$\mathrm{NF}-\kappa \mathrm{B}$ is mainly expressed in vascular smooth muscle cells, vascular endothelial cells and cardiomyocytes. Studies have shown that NF- $\kappa$ B plays key roles in the pathogenesis of cellular inflammation, proliferation and apoptosis $(15,16)$. When endotoxin is present in the blood, it can make the body cells produce a large number of reactive oxygen and free radicals, thus activating the NF- $\kappa \mathrm{B}$ signaling pathway to damage cells (17). TNF- $\alpha$, IL-1 and IL-6 are common inflammatory factors with anti-infection, antitumor, immune regulation and
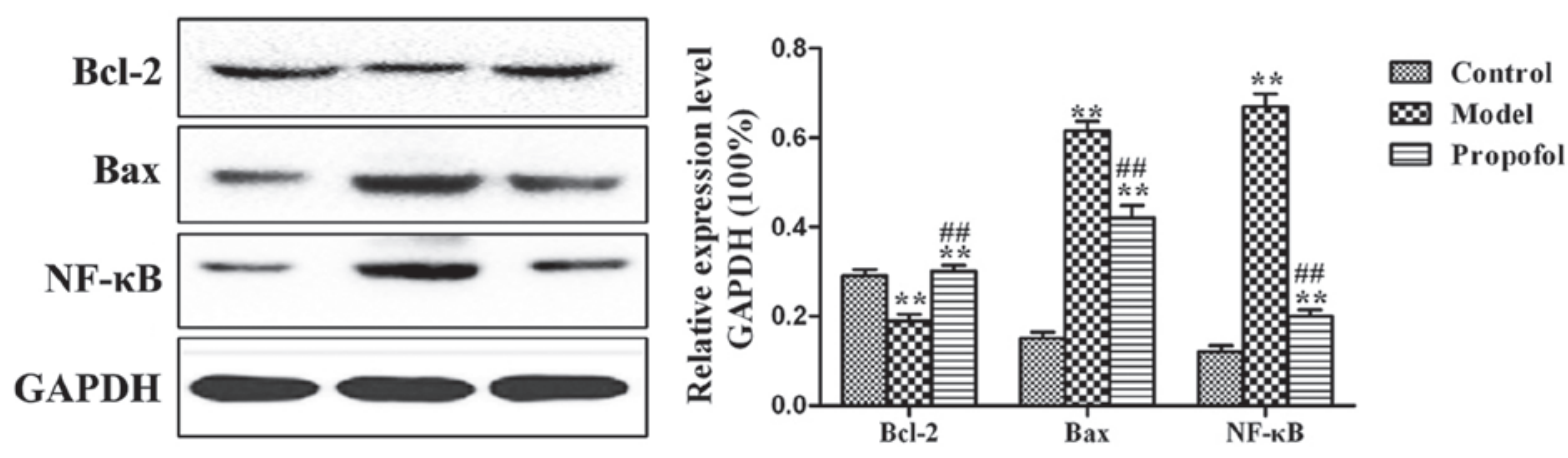

Figure 3. Western blot results for $\mathrm{NF}-\kappa \mathrm{B}, \mathrm{Bax}$ and $\mathrm{Bcl}-2$ protein levels in the three experimental groups. ${ }^{* *} \mathrm{P}<0.01$ comparison between the control and either the model or the propofol groups. ${ }^{\#} \mathrm{P}<0.01$ comparison between the model and the propofol groups. 


\section{Control}

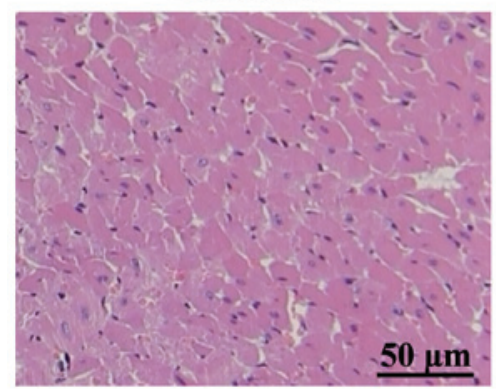

Model

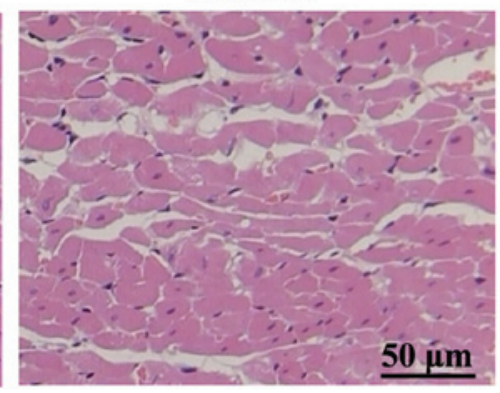

Propofol

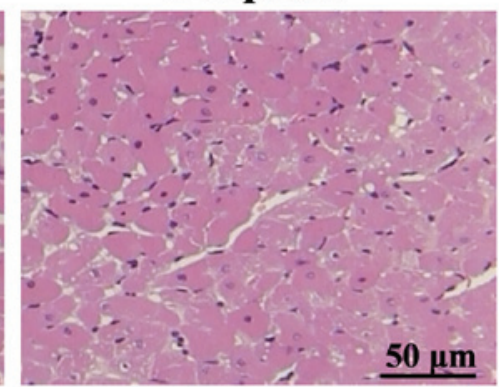

Figure 4. H\&E staining of myocardium samples in the three groups showing various degrees of injury. Myocardial tissues in the model group exhibit the most damage, followed by those in the propofol group.

other biological effects. Certain stimuli in the body, lead to increased inflammatory factors causing tissue damage and exacerbations of present conditions (18). TNF- $\alpha$ mediates the inflammatory response, and can be used as an important indicator of inflammation and tissue damage. TNF- $\alpha$ is derived from monocytes, macrophages, $\mathrm{T}$ lymphocytes and neutrophils. TNF- $\alpha$ leads to synthesis of a large number of NO and oxygen free radicals by its stimulation of i-NOS, thus resulting in cell membrane lipid peroxidation damage in tissues (19). IL-6 is mainly produced by activated neutrophils, endothelial or vascular smooth muscle cells. It is a factor with various biological activities, know to contribute to the development of cardiac dysfunction caused by myocardial ischemia-reperfusion injury (20). IL-1 can stimulate the biosynthesis of other inflammatory cytokines, but also enhances the sensitivity of tissue cells to TNF- $\alpha$ (21).

$\mathrm{NF}-\kappa \mathrm{B}$ can affect the release of inflammatory factors, such as IL-1, IL-6 and TNF- $\alpha$; in turn, IL-1, IL-6 and TNF- $\alpha$ can affect the activity of NF- $\mathrm{BB}$ in a biological feedback loop (22). The Bcl-2 family of proteins is part of a bigger mitochondrial apoptotic pathway. Anti-apoptotic proteins mainly include $\mathrm{Bcl}-2$ and $\mathrm{Bcl}-\mathrm{xl}$ (23). Bax is a pro-apoptotic protein that can destroy the mitochondrial bilayer structure, form perforated channels, increase membrane permeability and promote the release of cytochrome $c$, thus activating the mitochondrial apoptotic signaling pathway (24).

In this study, we hypothesized that propofol protects against endotoxin-induced myocardial injury through its inhibition of the NF- $\kappa \mathrm{B}$-mediated inflammation. The changes in the levels of IL-1, IL-6 and TNF- $\alpha$ in serum detected in our study are in agreement with the results of an study, which suggested that these factors play important roles in the myocardial injury caused during myocardial ischemia reperfusion (11). Since the $\mathrm{NF}-\kappa \mathrm{B}$ mRNA expression levels in myocardial tissues in rats treated with propofol were significantly lower than those in the model group our findings suggest that increased NF- $\kappa \mathrm{B}$ levels can lead to damage to the vascular endothelial and myocardial cells (25). In addition, we found that the protein expression levels of $\mathrm{NF}-\kappa \mathrm{B}$ and Bax in the propofol group were significantly lower than those in the model group rats, and the Bcl-2 protein expression levels were significantly higher in the propofol group. These findings agree with the results of a study showing that quercetin reduces apoptosis of myocardial cells through downregulating the expression of
Bax and upregulating the expression of Bcl-2 (26). Finally, the direct observation of the myocardial injury in the rat hearts by $H \& E$ staining proved that the myocardium of rats in the model group presented clear damage, while that of rats in the propofol group was much less injured.

In conclusion, propofol can protect against endotoxininduced myocardial injury through its inhibition of the $\mathrm{NF}-\kappa \mathrm{B}-$ mediated inflammation and its resulting reduced expression levels of IL-1, IL-6 and TNF- $\alpha$.

\section{References}

1. Tang J, Sun Y, Wu WK, Zhong T, Liu Y, Xiao J, Tao T, Zhao Z and Gu M: Propofol lowers serum PF4 level and partially corrects hypercoagulopathy in endotoxemic rats. Biochim Biophys Acta 1804: 1895-1901, 2010.

2. Tang J, Chen X, Tu W, Guo Y, Zhao Z, Xue Q, Lin C, Xiao J, Sun $\mathrm{X}$, Tao T, et al: Propofol inhibits the activation of p38 through up-regulating the expression of annexin A1 to exert its anti-inflammation effect. PLoS One 6: e27890, 2011.

3. Liu J, Zhao S, Tang J, Li Z, Zhong T, Liu Y, Chen D, Zhao M, Li Y, Gong X, et al: Advanced glycation end products and lipopolysaccharide synergistically stimulate proinflammatory cytokine/ chemokine production in endothelial cells via activation of both mitogen-activated protein kinases and nuclear factor-kappaB FEBS J 276: 4598-4606, 2009.

4. Nduka OO and Parrillo JE: The pathophysiology of septic shock. Crit Care Nurs Clin North Am 23: 41-66, 2011.

5. Van Amersfoort ES, Van Berkel TJ and Kuiper J: Receptors, mediators, and mechanisms involved in bacterial sepsis and septic shock. Clin Microbiol Rev 16: 379-414, 2003.

6. Brunkhorst FM and Reinhart K: Diagnosis and causal treatment of sepsis. Internist (Berl) 50: 810-816, 2009 (In German).

7. Barrientos-Vega R, Mar Sánchez-Soria M, Morales-García C, Robas-Gómez A, Cuena-Boy R and Ayensa-Rincon A: Prolonged sedation of critically ill patients with midazolam or propofol: Impact on weaning and costs. Crit Care Med 25: 33-40, 1997.

8. Romero-Bermejo FJ, Ruiz-Bailen M, Gil-Cebrian J and HuertosRanchal MJ: Sepsis-induced cardiomyopathy. Curr Cardiol Rev 7: $163-183,2011$

9. Prakanrattana U and Suksompong S: Comparision of propofol and fentanyl for surgical repair of congenital cardiac defects. Med Assoc Thai 85: 807-814, 2009.

10. Thomson IR, Harding G and Hudson RJ: A comparison of fentanyl and propofol in patients undergoing coronary artery bypass graft surgery. J Cardiothorac Vasc Anesth 14: 652-656, 2000.

11. Taniguchi T, Kanakura $\mathrm{H}$ and Yamamoto K: Effects of posttreatment with propofol on mortality and cytokine responses to endotoxin-induced shock in rats. Crit Care Med 30: 904-907, 2002.

12. He ZW, Qin YH, Wang ZW, Chen Y, Shen Q and Dai SM: HMGB1 acts in synergy with lipopolysaccharide in activating rheumatoid synovial fibroblasts via p38 MAPK and NF- $\mathrm{BB}$ signaling pathways. Mediators Inflamm 2013: 596716, 2013. 
13. Zhao P, Turdi S, Dong F, Xiao X, Su G, Zhu X, Scott GI and Ren J: Cardiac-specific overexpression of insulin-like growth factor I (IGF-1) rescues lipopolysaccharide-induced cardiac dysfunction and activation of stress signaling in murine cardiomyocytes. Shock 32: 100-107, 2009.

14. Chu CH, David Liu D, Hsu YH, Lee KC and Chen HI: Propofol exerts protective effects on the acute lung injury induced by endotoxin in rats. Pulm Pharmacol Ther 20: 503-512, 2007.

15. Müller DN, Mervaala EM, Dechend R, Fiebeler A, Park JK, Schmidt F, Theuer J, Breu V, Mackman N, Luther T, et al: Angiotensin II (AT(1)) receptor blockade reduces vascular tissue factor in angiotensin II-induced cardiac vasculopathy. Am J Pathol 157: 111-122, 2000.

16. Speir E: Cytomegalovirus gene regulation by reactive oxygen species. Agents in atherosclerosis. Ann NY Acad Sci 899: 363-374, 2000.

17. von Dessauer B, Bongain J, Molina V, Quilodrán J, Castillo R and Rodrigo R: Oxidative stress as a novel target in pediatric sepsis management. J Crit Care 26: 103.e1-103.e7, 2011

18. Wang Y, Yu X, Wang F, Wang Y, Wang Y, Li H, Lv X, Lu D and Wang $\mathrm{H}$ : Yohimbine promotes cardiac NE release and prevents LPS-induced cardiac dysfunction via blockade of presynaptic a2A-adrenergic receptor. PLoS One 8: e63622, 2013.

19. Suzuki Y, Deitch EA, Mishima S, Lu Q and Xu D: Inducible nitric oxide synthase gene knockout mice have increased resistance to gut injury and bacterial translocation after an intestinal ischemiareperfusion injury. Crit Care Med 28: 3692-3696, 2000.

20. Tanhehco EJ and Sabbah HN: The role of IL-6 in experimenta and clinical heart failure. Inflamm Card Dis 2003: 143-151, 2003.
21. Obetholzer A, Obetholzer C and Moldawer LL: Cytokine signaling - regulation of the immune response in normal and critically ill states. Crit Care Med 28 (Suppl 4): N3-N12, 2000.

22. Peng J, Gurantz D, Tran V, Cowling RT and Greenberg BH: Tumor necrosis factor-alpha-induced AT1 receptor upregulation enhances angiotensin II-mediated cardiac fibroblast responses that favor fibrosis. Circ Res 91: 1119-1126, 2002.

23. Chittenden T, Harrington EA, O'Connor R, Flemington C, Lutz RJ, Evan GI and Guild BC: Induction of apoptosis by the Bcl-2 homologue Bak. Nature 374: 733-736, 1995.

24. Schulz JB, Weller M and Moskowitz MA: Caspases as treatment targets in stroke and neurodegenerative diseases. Ann Neurol 45: 421-429, 1999

25. Jones WK, Brown M, Ren X, He S and McGuinness $M$ NF-kappaB as an integrator of diverse signaling pathways: The heart of myocardial signaling? Cardiovasc Toxicol 3: 229-254, 2003.

26. Zeng Y, Qi L, Li S, Hou Y, Xu W, Wang H, Zhao X and Sun C: A metabonomic analysis of the effect of quercetin on toxicity induced by chronic exposure to low-level dichlorvos in rat plasma. Mol Biosyst 10: 2643-2653, 2014.

This work is licensed under a Creative Commons Attribution-NonCommercial-NoDerivatives 4.0 International (CC BY-NC-ND 4.0) License. 